\title{
A Con Artist: Phenylphenoxybenzamide is not a Glycosyltransferase Inhibitor
}

Dr. Gjalt G. Wybenga ${ }^{1 *}$, Wei-Shen $\mathrm{Wu}^{1,2}$

Genomics Research Center, Academia Sinica, 128 Academia Road, Section 2, Nankang, Taipei, 115, Taiwan ${ }^{1} \&$ Graduate Institute of Life Sciences, National Defense Medical Center, 161 Minquan E. Road, Section 6, Neihu, Taipei 114, Taiwan²

*corresponding author: ggwybenga@yahoo.com

\begin{abstract}
To combat bacterial resistance against antibiotics, glycosyltransferase inhibiting molecules, which block the synthesis of the pre-cursor of the bacterial cell wall, need to be discovered and developed. In this study, we demonstrate that phenylphenoxybenzamide, a salicylanilide, is not a glycosyltransferase inhibiting molecule, despite claims in literature to the contrary, and through our work show that glycosyltransferase construct choice and detergent choice are crucial parameters to consider when designing glycosyltransferase assays that aim to discover and develop molecules that inhibit these types of enzymes.
\end{abstract}

Attribution: crystallography, enzyme assay design and paper writing (GGW), DNA manipulations, enzyme assay co-design and execution (WSW). 


\section{Introduction}

The emergence of bacterial resistance to common antibiotics [1] has prompted initiatives to search for new antibiotics against existing antibiotic targets, for example, enzymes that synthesize peptidoglycan. Peptidoglycan provides mechanical strength to Gram-positive and Gram-negative bacteria, which allows these bacteria to withstand osmosis-induced turgor pressure caused by ionic strength fluctuations in the bacterium's environment [2]. Peptidoglycan is synthesized from GlcNAc-MurNAc-pentapeptide-diphosphate-undecaprenyl (lipid II) [3, 4] by class A penicillin binding proteins (PBPs) [5]. The N-terminal domain of a PBP encodes a glycosyltransferase (GT). This GT catalyzes a cation cofactor-dependent reaction that results in the formation of a $\beta-1,4$ covalent bond between the C4 O-atom of the GlcNAc sugar of lipid II (bound in the acceptor pocket of the active site of the GT) and the C1-atom of the MurNAc sugar of lipid II (bound in the donor pocket). The product subsequently translates through the active site of the GT, after which another lipid II molecule binds the now vacant acceptor pocket. Consecutive reactions result in a lipid II polymer [6, 7], which during the GT-catalyzed reaction, is integrated into pre-existing peptidoglycan by the C-terminal domain of the PBP that catalyzes a transpeptidase (TP) reaction [5]. While PBPs build up and strengthen the peptidoglycan layer that surrounds a bacterium, lytic transglycosylases weaken the peptidoglycan layer by cleaving the $\beta-1,4$ covalent bond created by PBPs [9]. Compounds that bind and inhibit the reactions catalyzed by PBPs will thus negatively affect the strength of the bacterial cell wall and are therefore sought after since they can be potentially used as antibiotics. $\beta$-lactam antibiotics inhibit the TP reaction catalyzed by PBPs, however bacteria have developed resistance to these types of antibiotics, rendering them less effective in treating bacterial infections $[9,10]$. Therefore attention has shifted towards molecules that inhibit the GT-catalyzed reaction by PBPs. Examples are moenomycins and moenomycin analogues [11], monosaccharides ACL20215 and ACL20964 [12], and lipid II substrate analogues [13, 14]. More recently, non-saccharide molecules, such as salicylanilides [15], Albofungin (a xanthone) and TAN1532B (a benzo[a]tetracene) were discovered to inhibit the GT-catalyzed reaction [16]. In this research we employ a monoglycosyltransferase from $S$. aureus (SaMGT), a class A PBP without a TP domain (CAZy: GT51), to reveal that phenylphenoxybenzamide (ppb, fig. 1 (3), a salicylanilide) is not a GT inhibitor, and in the process establish GT assay design principles that will facilitate GT inhibitor identification and development. 


\section{Materials and Methods}

Transformation and Expression of $\triangle 28-269$ and $\triangle 68-269$ SaMGT - $40 \mathrm{ng}$ of DNA (pET15b encoding truncated SaMGT with an N- $(\Delta 28-269$, table 1 (2)) or C-terminal linker $(\Delta 68-269$, table 1 (3)) containing a His 6 -tag (confirmed by sequencing)) was added to a vial containing $100 \mu$ thawed E. coli $\mathrm{B} 121(\mathrm{DE} 3)$ competent cells (RBC Biosciences) kept at $4{ }^{\circ} \mathrm{C}$. The suspension was mixed, transferred to a water bath for transformation $\left(42^{\circ} \mathrm{C}, 1 \mathrm{~min}\right)$, returned to ice, and finally pipetted onto a TB agar plate containing $100 \mu \mathrm{g} / \mathrm{ml}$ carbenicillin. The plate was incubated overnight at $37^{\circ} \mathrm{C}$ and bacterial colonies used to inoculate a $100 \mathrm{ml}$ TB pre-culture $(100 \mu \mathrm{g} / \mathrm{ml}$ carbenicillin, same temperature, $180 \mathrm{rpm}$ ). After $17 \mathrm{~h}, 5 \mathrm{ml}$ pre-culture was used to inoculate $1 \mathrm{~L}$ pre-heated TB medium (50 $\mu \mathrm{g} / \mathrm{ml}$ carbenicillin, added prior to inoculation, $37^{\circ} \mathrm{C}, 180 \mathrm{rpm}$ ) and at OD 0.5-0.6 (reached within $3 \mathrm{~h}$ ) $0.36 \mathrm{~g}$ of IPTG powder was added to induce expression of $\Delta 28-269$ (2MGT, Table 1) or $\Delta 68-269 \mathrm{SaMGT}$ (6MGT). After $3 \mathrm{~h}$ the medium was collected and centrifuged to harvest the E. coli cells, after which the cell pellet was collected, frozen $\left(-20^{\circ} \mathrm{C}\right)$ and stored until further use.

Purification of $2 M G T$ - To each gram of frozen cell pellet $10 \mu 11 \mathrm{mg} / \mathrm{ml}$ DNase I (Sigma) and $20 \mu \mathrm{l} 50 \mathrm{mg} / \mathrm{ml}$ lysozyme were added, then $30 \mathrm{ml}$ buffer A (20 mM Tris-HCl pH 8, $200 \mathrm{mM}$ $\mathrm{NaCl}$ ) and one cOmplete EDTA-free protease inhibitor tablet (Sigma). After thawing, and homogenization by vortexing, the cell solution was passed thrice through a microfluidizer device. The volume of the flow-through was then adjusted to $50 \mathrm{ml}$ with buffer A, n-Decyl- $\beta$-DMaltopyranoside (DM, Anatrace) powder was added (483 mg, $20 \mathrm{mM}$ ), incubated ( $2 \mathrm{~h}$, RT, Intelli Mixer, $4 \mathrm{rpm}$ ) and centrifuged (Eppendorf 5810R, rotor F-34-6-38, $10.000 \mathrm{rpm}, 10 \mathrm{~min}$ ) to remove non-solubilized material. The supernatant was decanted, centrifuged once more and loaded onto a 1 ml HisTrap HP column with an ÄKTA FPLC pre-equilibrated with buffer B (20 mM Tris-HCl pH 8, $200 \mathrm{mM} \mathrm{NaCl}, 50 \mathrm{mM}$ imidazole $\mathrm{pH} 8$ and $2 \mathrm{mM} \mathrm{DM}$ ). The column was washed with buffer B (15 column volumes), disconnected from the FPLC system, and loaded with $1.1 \mathrm{ml}$ buffer B mixed with $20 \mu \mathrm{l}$ thrombin ( 1 unit thrombin per $\mu 1 \mathrm{X}$ PBS) and incubated overnight $\left(23^{\circ} \mathrm{C}\right)$ to release bound 2MGT. After $20 \mathrm{~h}$ the column was reconnected to the FPLC system, washed with buffer B, the flow-through collected, concentrated (Amicon, $10.000 \mathrm{MWCO}$ ) and further purified with a Superdex 200 10/300 GL column (GE Healthcare) equilibrated in $200 \mathrm{mM} \mathrm{NaCl}, 2 \mathrm{mM}$ DM and 20 mM Tris-HCl pH 8 (buffers C) or Na HEPES pH 8 (buffer C'). The purified protein (Figs. S1 \&S2) was collected, and either used for crystallization experiments after concentration (buffer C), or frozen $\left(-20^{\circ} \mathrm{C}\right)$ and after thawing used for enzyme assays (buffer $\left.\mathrm{C}^{\prime}\right)$. 
Crystallization of $2 M G T$ - For crystallization experiments, purified 2MGT, of which the protein concentration was determined with the Bradford method [17], was mixed with buffer C and bicelle solution resulting in a $15 \mathrm{mg} / \mathrm{ml}$ protein, $3 \% \mathrm{wt} / \mathrm{vol}$ bicelle solution, mixture. A mosquito crystallization robot (TTP Labtech) was employed to set up sitting drop vapor diffusion plates (MRC 2, Hampton) to screen for crystal growth in drops consisting of $0.15 \mu \mathrm{l}$ protein/bicelle solution and $0.15 \mu \mathrm{l}$ well solution. Each well $(60 \mu \mathrm{l})$ of the sitting drop plate contained 1 of 96 different combinations of $100 \mathrm{mM} \mathrm{MgCl}_{2}$ (Hampton), $0.1 \mathrm{M} \mathrm{Na}$ HEPES pH 8 (Hampton), and 1234 \% wt/vol PEG200-1500 (Hampton, Sigma, Fluka). The plates were sealed with clear sealing tape (Hampton) and immediately transferred to the cold room $\left(4^{\circ} \mathrm{C}\right)$.

Preparation of bicelle solution - To make bicelle solution [18] 5 mg CHAPS detergent (GE), 15 mg DMPC (Avanti Polar Lipids) and $100 \mu$ ultra-pure water (Milli-Q) were mixed, heated to $42{ }^{\circ} \mathrm{C}$ (10 $\left.\mathrm{min}\right)$, vortexed, put on ice $(10 \mathrm{~min})$, vortexed again, and these steps repeated until all solid material was dissolved. The solution was kept on ice for use in crystallization experiments, or was frozen $\left(-20^{\circ} \mathrm{C}\right)$.

Diffraction data processing - The diffraction data collected from a 2MGT crystal were indexed with Mosflm (space group P1) [19], scaled and merged with Scala, after which a selfrotation function was calculated with Molrep. This revealed the presence of three perpendicular 2fold axes. The data were indexed, scaled and merged again (P222) and the presence of two screw axes established along a and $\mathbf{c}$ (confirmed with Pointless). To generate P $2{ }_{1} 22$ from P222 Reindex was applied with operator $\mathrm{h}=\mathrm{l}, \mathrm{k}=\mathrm{h}, \mathrm{l}=\mathrm{k}$. The data were then truncated (ellipsoidally) and scaled (anisotropically) using the diffraction anisotropy server (https://services.mbi.ucla.edu/anisoscale/) [20] and reflections assigned to $\mathrm{R}_{\text {free }}(5.6 \%)$ with Uniquefy. The solvent content was determined with Matthews [21] and for phasing Phaser (for molecular replacement) [22] was employed with an input model based upon the model associated with PDB code 3VMQ [23] (without the TMdomain). The model was subsequently refined with Refmac [24], and manipulated with Coot [25]. Scala, Molrep, Pointless, Reindex, and Uniquefy were accessed via the CCP4 software suite [26]. Refinement statistics for the model are reported in Table S1.

Construction, transformation, expression and purification of transmembrane domain-less $6 M G T$ - The transmembrane (TM) domain of 2MGT was identified with Phobius [27] (see Results) and two primers 5' CATGCCATGGATAATGTGGATGAACTAAG $-3^{\prime}$ (forward) and 5', 


\section{CGCGGATCCTCATCAGTGATGATGATGATGATGGCTGCTGCCGCTGCCGCGCGGCACCA} GACGATTTAATTGTGACATAGCC -3' (reverse) designed to construct 6MGT from the 2MGT encoding pET15b plasmid. After PCR the DNA product was purified, restricted with NcoI and BamHI, ligated into a pET15b vector and sequenced. After transformation of E. coli B121(DE3) cells with the 6MGT encoding plasmid, 6MGT was expressed and purified as described (2MGT) although the last purification step utilized a Superdex75 10/300 GL column equilibrated in buffer C' without DM (Figs. S1\&S2).

Enzyme assay design- To test whether purified MGT (2MGT or 6MGT) was able to polymerize NDB-lipid II (Fig. 1 (1)), NBD-lipid II (lipid II) was pipetted into an eppendorf tube from a stock solution dissolved in $\mathrm{MeOH}$. The tube was transferred into a fume-hood, and the $\mathrm{MeOH}$ allowed to evaporate. A buffer, a catalyst, a detergent and/or organic solvents were added followed by purified enzyme. This resulted in an enzyme assay volume of $20 \mu 1$, an enzyme concentration of $0.2 \mu \mathrm{M}$ and a lipid II concentration of $4 \mu \mathrm{M}$. The eppendorf tube was then, without delay, transferred into an eppendorf thermomixer R (1400 rpm), and the enzymatic reaction (after time) stopped by the addition of $1 \mu \mathrm{M}$ moenomyin A (moeA, fig. 1 (2), [28]). Next, $200 \mu \mathrm{g}$ lysozyme was added to convert lipid II polymer into NBD-GlcNAc-MurNAc-dissacharide (room temperature, $2 \mathrm{~h}$ ) and the mixture analyzed as described by $\mathrm{Wu}$ et al. [16]. To test the inhibition of MGT by moeA, moeA was added to the enzyme assay solution prior to adding purified enzyme. To test whether MGT was inhibited by ppb (Fig. 1 (3)) or TAN1532B (Fig. S4 (4), 2MGT only) either compound (dissolved in $\mathrm{MeOH}$ ) was added to an eppendorf tube together with lipid II, then placed in a fume-hood, and after evaporation of $\mathrm{MeOH}$, used to assay enzymatic activity (Figs. 4, 5 and 6).

Growth of S. aureus cells and extraction of S. aureus lipids - S. aureus strain ATCC 29213 was used to inoculate $5 \mathrm{ml}$ neutral broth $\left(37^{\circ} \mathrm{C}\right)$. The cells were grown for $19 \mathrm{~h}$, after which the preculture was used to inoculate $2 \mathrm{~L}$ neutral broth, and continued for $19 \mathrm{~h}\left(37^{\circ} \mathrm{C}\right)$. The cells were then harvested and frozen $\left(-80^{\circ} \mathrm{C}\right)$. To $0.9 \mathrm{~g} \mathrm{~S}$. aureus cell pellet (from $200 \mathrm{ml}$ culture) ultra-pure water was added, as well as $\mathrm{NaCl}(500 \mathrm{mM})$, lysozyme $(100 \mathrm{mg})$ and DNase I (0.1 mg). The suspension $(2.5 \mathrm{ml})$ was incubated for $2 \mathrm{~h}$ at $37{ }^{\circ} \mathrm{C}$, vortexed every half hour, and transferred into a $100 \mathrm{ml}$ glass vial. While vortexing, $50 \mathrm{ml}$ hexane isopropanol (3:2 [29]) was added to the cell suspension. The mixture was left to settle for $30 \mathrm{~min}$ and the solvent harvested. Samples were taken for thin layer chromatography analysis (Fig. S3). The stationary phase was silica gel 60G F254 (Merck), the mobile phase was a mixture of chloroform (65\%), methanol (25\%) and acetic acid (10\%), and staining of the phospholipids was performed with $\mathrm{CuSO}_{4}(100 \mathrm{mg} / \mathrm{ml})$ [30]. The solvent was 
subsequently roto-evaporated to dry-ness, which yielded $30 \mathrm{mg}$ S. aureus lipid powder. A $2 \%$ $\mathrm{wt} / \mathrm{vol} S$. aureus lipid solution was subsequently made by adding an appropriate volume of ultrapure water followed by rigorous vortexing.

Dynamic light scattering - To investigate the dispersity of size exclusion purified 6MGT, the enzyme was diluted with buffer (20 mM Na HEPES pH 7.5, $1 \mathrm{mM} \mathrm{MnCl} 2,200 \mathrm{mM} \mathrm{NaCl}$ ) to 0.1 $\mathrm{mg} / \mathrm{ml}$, pipetted into a quartz cuvette (QS $3 \mathrm{~mm}$, Hellma) and measured $\left(30^{\circ} \mathrm{C}\right)$ with a Zetasizer Nano ZS dynamic light scattering system (Fig. 3).

Modelling - To predict a potential interaction between ppb and the quarternary structure of TM-less 68MGT (Fig. 2D, PDB code 3HZS, a trimer), ppb was drawn in ChemDraw and topologies generated with PRODRG [31] then together with the protein target (without bound moeA, $\mathrm{PO}_{4}$, and $\mathrm{H}_{2} \mathrm{O}$ ) submitted to SwissDock [32] (Fig. 7).

\section{Results}

SaMGT and SaMGT truncates - In this study we used a monoglycosyltransferase (MGT) from S. aureus (SaMGT) to investigate how a non-saccharide salicylanilide (Fig. 1 (3), ppb) inhibited the SaMGT-catalyzed lipid II polymerization reaction, as a general model for how the PBP GT-catalyzed reaction was inhibited by salicylanilides. SaMGT is a $31 \mathrm{kDa}$ enzyme (Table 1 (1)) that is composed of three domains: a cytoplasmic domain (residues 1-41), a transmembrane (TM) domain (residues 42-64, ILLKILLTILIIIALFIGIMYFL, fig. 2A), and a membrane-associated periplasmic domain (residues 65-269) that catalyzes a lipid II polymerization reaction. SaMGT degrades during purification (data not shown), unlike $\Delta 28-269$ SaMGT (2MGT, table 1 (2)). A 3D structure of 2MGT has been elucidated (PDB code 3VMQ [23], and this research (Table S1, fig. 2A) as well as a 3D structure of a TM-less $\Delta 68-268 \mathrm{SaMGT}$ (68MGT, table 1 (4), PDB code 3HZS, fig. 2B) with bound moenomycin A (moeA)) [33]. 68MGT crystallizes as a trimer (space group $\mathrm{H}_{2}$, fig. 2D), with the interface between chains A, B and C burying $400 \AA^{2}$ out of a total surface area of $\sim 11000 \AA^{2}$ per chain (PISA [34]), whereas 6MGT (table 1 (3)), a TM-less SaMGT construct analogous to TM-less 68MGT, oligomerizes in solution (Fig. 3), just as TM-less $\Delta 68-268$ (table 1 (5)) [35] and TM-less $\Delta 68-269 \mathrm{SaMGT}$ (table 1 (6)) [36]. 
Structural investigation into $2 M G T$ ppb inhibition - In an attempt to gain insight into the inhibition of the SaMGT-catalyzed reaction by ppb (Fig. 1 (3)), 2MGT was purified as described (for reasons of simplicity) and initially crystallized in the absence of ppb. Several well diffracting protein crystals were obtained that crystallized in an orthorhombic space group. 2MGT crystallizes as a monomer (Table S1) and its 3D structure is similar to the 3D structure of 2MGT deposited under PDB code 3VMQ (2 molecules per ASU) [23] with an RMSD over $180 \mathrm{C} \alpha$-atoms of $0.4 \AA$ (chain $\mathrm{A}$ of $3 \mathrm{VMQ}$ ) and $0.7 \AA$ (chain $\mathrm{B}$ ). The $3 \mathrm{D}$ structure is further similar to the $3 \mathrm{D}$ structure of moeA bound TM-less 68MGT with an RMSD of $0.8 \AA$ over $161 \mathrm{C} \alpha$-atoms (monomer A). The 2MGT 3D structure has three three flexible elements, which are, as a consequence, only partly defined by electron density. One of these elements is the N-terminal $\alpha$-helix (Fig. 2A). The other two elements are formed by flexible structural elements comprised of amino acids 109 through 132 (element A, hypothesized to be important for glycan processivity [37], fig. 2B) and amino acids 145 through 154 (element B, fig. 2B). However, when attempts were subsequently made to elucidate a $3 \mathrm{D}$ structure of $2 \mathrm{MGT}$ with bound ppb (after overnight exposure of purified 2MGT to a 50-fold molar excess of ppb (as powder) and co-crystallization of 2MGT with ppb) the elucidated 2MGT $3 \mathrm{D}$ structure failed to reveal bound $\mathrm{ppb}$.

Ppb inhibition of $2 M G T$ - To verify whether ppb inhibited the SaMGT-catalyzed reaction, the enzymatic activity of purified 2MGT was tested using the protocol published by Wu et al. [16]. This revealed that 2MGT was active and polymerized NBD-lipid II (lipid II) and that the presence of moeA or ppb in the assay condition led to the inhibition of the 2MGT-catalyzed reaction (data not shown). The enzyme assay conditions were then altered to more closely resemble the assay conditions used by Terrak et al. [35]. 2MGT was found to be active and to be inhibited by moeA and ppb (Fig. 4 (A1-A5)). $\mathrm{C}_{10} \mathrm{E}_{8}$ (octaethylene glycol monodecyl ether, decyl-PEG) was subsequently substituted for n-decyl- $\beta$-D-maltopyranoside (DM). 2MGT polymerized lipid II, moeA inhibited 2MGT, but ppb did not inhibit the 2MGT-catalyzed lipid II polymerization reaction (Fig. 4 (B1-B5)).

Isolation of lipids from S. aureus cells and inhibition of $2 M G T$ by $p p b$ - To further investigate this result, $\mathrm{C}_{10} \mathrm{E}_{8}$ and $\mathrm{DM}$ were substituted for lipids directly isolated from $S$. aureus cells (Fig. S3). The S. aureus extract contained two types of lipids with $\mathrm{R}_{\mathrm{f}}$ values similar to lipids present in the E. coli total lipid extract, and one lipid (nearest to the spot origin, presumably lysylphosphatidylglycerol (LPE) [30]) not present in the E. coli lipid extract and thus specific to $S$. aureus. 2MGT polymerized the lipid II substrate (Fig. 4 (C1)) and the presence of moeA in the 
assay condition led to the inhibition of 2MGT (Fig. 4 (C5), Fig. 5C). 2MGT was not inhibited when the enzyme assay condition contained ppb (Fig. 4, C2-C4), but 2MGT was inhibited in the presence of TAN1532B (Fig. S4 (4), fig. 5B).

Inhibition of TM-less 6MGT by ppb and modelling of the 68MGT ppb interaction - A final experiment was subsequently devised and ppb inhibition of TM-less 6MGT tested in an enzyme assay condition (without detergent) in which 6MGT oligomerized (Fig. 3). 6MGT was active and polymerized lipid II (Fig. 6A), was inhibited when the assay condition contained moeA (Fig. 6C), and, surprisingly when the assay condition contained ppb (Fig. 6B). The interaction between ppb and oligomeric $6 \mathrm{MGT}$ was modeled with the 3D structure of trimeric $68 \mathrm{MGT}$, which revealed ppb bound, in various orientations (models), in a hydrophobic pocket formed by chain A, B and C of the 68MGT trimer (Fig. 7A, C).

\section{Discussion}

Structural investigations into glycosyltransferase inhibition by ppb, a non-saccharide salicylanilide inhibitor - In this study we attempted to elucidate a 3D structure of $\Delta 28-269$ SaMGT (2MGT) with bound phenylphenoxybenzamide (Fig. 1 (3), ppb) with the aim to facilitate structurebased salicylanilide (antibiotic) design. Despite multiple attempts, a 3D structure of 2MGT with bound ppb was eventually not elucidated. To explain this lack of success, it was hypothesized that 2MGT had not bound ppb during ppb treatment and co-crystallization or had bound ppb, but had bound ppb through its flexible TM-domain (hydrophobic) and therefore could not be resolved. Alternatively, it was hypothesized that 2MGT had bound ppb, but could not maintain bound ppb upon crystallization, as exemplified by the inability of crystallized 2MGT to bind moenomycin A (moeA) (Fig. 2C) or as a consequence of crystallization induced non-specific contacts [38], as exemplified by element A (in)flexibility in the 3D structures of 2MGT and $\Delta 28-268$ SaMGT (68MGT) (Fig. 2B). Last, it was hypothesized that ppb was not an inhibitor of 2MGT, but appeared to be, as a consequence of the protocol used [16] to assay glycosyltransferase (GT) ppb inhibition.

Ppb is not a GT inhibitor - To test this hypothesis, we employed a) 2MGT to exclude the possibility that enzyme assay results were influenced by domains found in structurally more complex PBPs (see Introduction) and b) varied enzyme assay conditions to probe whether ppb inhibition of 2MGT enzymatic activity was assay condition-dependent. The protocol outlined by 
Wu et al. [16] was initially used, and the result showed that ppb inhibited 2MGT (data not shown), which suggested that ppb was indeed a GT inhibitor [15]. The enzyme assay condition was then altered to resemble the enzyme assay condition used by Terrak et al. [36] to investigate the kinetic properties of TM-less $\Delta 68$-268 SaMGT (Table 1 (6)). However, organic solvents were omitted to avoid assay component concentration changes as a consequence of $\mathrm{MeOH}$ evaporation, and to avoid the possibility that the solvents affected the 2MGT native structure [39]. The results showed that 2MGT was active, was inhibited by moeA and was inhibited by ppb (Fig. 4 (A1-A5)). This experiment revealed that the inhibition of $2 \mathrm{MGT}$ by ppb, despite substantial assay condition changes, could be reproduced. However, upon termination of the 2MGT-catalyzed reaction, and analysis of the reaction mixture contents, a substantial amount of lipid II substrate remained unconverted (Fig. 4 (A1)). This was attributed to the temperature used to perform the assay $\left(30{ }^{\circ} \mathrm{C}\right)$ and to lipid II substrate aggregation in the absence of organic solvents [40]. Next, $\mathrm{C}_{10} \mathrm{E}_{8}$ was substituted for the disaccharide-based detergent n-decyl- $\beta$-D-maltopyranoside (DM) and the experiment repeated. 2MGT was active, 2MGT was inhibited by moeA, but 2MGT was not inhibited by ppb (Fig. 4 (B1-B5)). These results suggested that ppb was not a GT inhibitor, contrary to earlier observations, and that ppb inhibition of 2MGT was detergent-dependent. For this reason, $\mathrm{C}_{10} \mathrm{E}_{8}, \mathrm{DM}$ and artificial detergents in general, were dispensed with, and substituted for lipids directly extracted from S. aureus cells (Fig. S3) via a method previously described by Hara et al. [40] and validated by Kolarovic et al. [41] with the aim to mimic the native lipid environment of $\mathrm{SaMGT}$, the bacterial plasma membrane. This allowed the enzyme assay time to be reduced from $\geq$ $2 \mathrm{hr}\left(\mathrm{C}_{10} \mathrm{E}_{8}\right.$ and $\left.\mathrm{DM}\right)$ to $\leq 10 \mathrm{~min}$ (Fig. $4(\mathrm{C} 1)$ ). A similar observation was made by Newman et al. [42], who showed that lactose permease enzymatic activity increased significantly when reconstituted into liposomes prepared from crude E. coli phospholipid extract instead of octyl- $\beta$-Dglucopyranoside. Under these enzyme assay conditions, 2MGT was inhibited by moeA (Fig. 4 (C5), Fig. 5C), but ppb failed to inhibit the 2MGT-catalyzed reaction (Fig. 4 (C2-C4)). Thus while moeA inhibited 2MGT effectively under all assay conditions in comparison to ppb, ppb inhibition of 2MGT was $\mathrm{C}_{10} \mathrm{E}_{8}$-dependent, which showed that ppb was not a genuine GT inhibitor, a conclusion further strengthened by the inhibition of 2MGT by TAN1532B (Fig. 5B) [16].

Ppb binds 6MGT and modelling of the 68MGT ppb interaction - To further validate this conclusion, 2MGT was substituted for TM-less 6MGT, which oligomerized under assay conditions without detergent (Fig. 3) in accordance with TM-less $\Delta 68-269$ [35] and $\Delta 68-268$ SaMGT [36]. 6MGT was active and polymerized lipid II, moeA inhibited 6MGT and, contrary to expectations, 6MGT was inhibited by ppb (Fig. 6B). However, inspection of the 3D structure of 2MGT revealed 
that it's periplasmic domain (6MGT) lacked a pocket lined with hydrophobic residues that could accommodate ppb. It was therefore hypothesized that ppb bound/sequestered lipid II. This was proven incorrect after $\mathrm{Wu}$ et al. [16] showed that TM-less and TP-less truncates of $A$. baumannii PBP1b and C. difficile PBP bound ppb in the absence of lipid II. The fact that 2MGT crystallized as a monomer, whereas TM-less $\Delta 68-268$ SaMGT (68MGT) crystallized as a trimer (Fig. 2D) and TM-less 6MGT, under assay conditions, assembled into oligomers, among which trimers (Figs. 2D \& 3) led to the hypothesis that ppb bound oligomeric rather than monomeric 6MGT. To investigate this hypothesis, a docking experiment was performed with 68MGT (trimer) and ppb, as a model for how a trimer of 6MGT may bind ppb. This experiment revealed that ppb bound a hydrophobic pocket lined by the F150's of chain A, B and C of 68MGT (I186 and L227 in CdPBP and AbPBP1b, respectively) and showed that bound ppb simultaneously occupied the moenocinol side chain binding pockets of moeA (Fig. 7B, D), which explained why ppb, under assay conditions, inhibited the 6MGT-catalyzed lipid II polymerization reaction. However, oligomerization of $\Delta 68-269$ and $\Delta 68$-268 SaMGT was shown to be detergent-sensitive $[35,36]$, and comparison of the 3D structure of $68 \mathrm{MGT}$ with that of $2 \mathrm{MGT}$ (Fig. 2D) showed that steric hindrance would prevent 2MGT monomers from assembling into the same configuration as 68MGT monomers upon trimerization. This suggested that 2MGT would not be able to bind ppb even in an oligomerization event, in contrast to 68MGT. For these reasons, ppb inhibition of 6MGT, under assay conditions, was concluded to represent an artifact. Our investigations thus reveal that construct choice, and detergent choice strongly affect GT assay results and show that it is imperative that GT assays are thoroughly validated before being applied to screen for GT inhibitors, in order to avoid falsepositives [43]. 


\section{Figures}

1

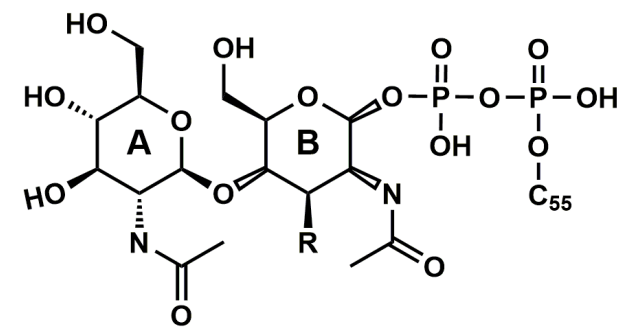

3<smiles>Cc1ccc(C(C)C)c(Oc2cc(Cl)ccc2NC(=O)c2cc(Br)cc(Br)c2O)c1</smiles>

Fig. 1: The chemical structures of NBD-lipid II (1) with 'R' representing a NBD-labeled lactoylpentapeptide (AEKAA) as shown in fig. 9B of Cheng et al. [15]. Moenomycin A (2), a lipid IV product analogue. 3,5-dibromo-N-[4-chloro-2-(5-methyl-2-propan-2-ylphenoxy)phenyl]-2hydroxybenzamide (ppb, 3, $\log \mathrm{P} 10.3$ ), a salicylanilide (Cheng et al. [15], table 12, compound 4231). Acquired from Vitas-M laboratory. Figure made with ChemDraw. 


\begin{tabular}{|c|c|c|c|c|c|}
\hline $\mathrm{Nr}$. & Construct & N-terminus & C-terminus & total number of amino acids & MW (kDa) \\
\hline 1 & SaMGT & MKRSDRYSNS & QQAMSQLNR & 269 & 31.459 \\
\hline 2 & $\Delta 28-269$ & GSHMQ $_{28}$ PVGKP & YQQAMSQLNR $_{269}$ & 246 & 28.388 \\
\hline 3 & $\Delta 68-269$ & $\mathrm{MD}_{68} \mathrm{NVDELRKI}$ & $\mathrm{MSQLNR}_{269} \underline{\mathrm{LVPR}}$ & 207 & 23.996 \\
\hline 4 & $\Delta 68-268$ & NLYFQGHMD $_{68} \mathrm{~N}$ & QYQQAMSQLN $_{268}$ & 209 & 24.234 \\
\hline 5 & $\Delta 68-269$ & $\mathrm{MGH}^{10} \mathrm{SSGHIEG}$ & YQQAMSQLNR $_{269}$ & 224 & 26.052 \\
\hline 6 & $\Delta 68-268^{*}$ & MGSSH ${ }^{6}$ SSGLV & YQQAMSQLNR $_{269}$ & 223 & 25.695 \\
\hline
\end{tabular}

Table 1: An overview of $S a M G T$ constructs used in different studies. 1) SaMGT. UniProtKB Q99T05. Shown for reference purposes. 2, 3) This study. The underlined amino acids were introduced after thrombin cleavage of a thrombin-cleavable linker containing a poly-histidine tag to facilitate nickel affinity chromatography purification. 4) The $S a$ MGT construct used to elucidate the 3D structure of TM-less $\triangle 68-268 \mathrm{SaMGT}(68 \mathrm{MGT})$ with bound moeA (PDB code 3HZS). 5, 6) SaMGT constructs used by Wang et al. [35] and Terrak et al. [36]. Both retain an N-terminal linker containing a poly-histidine tag $\left(\mathrm{H}^{10}, \mathrm{H}^{6}\right.$, respectively). *The primer translates to $\mathrm{R} 269$. 


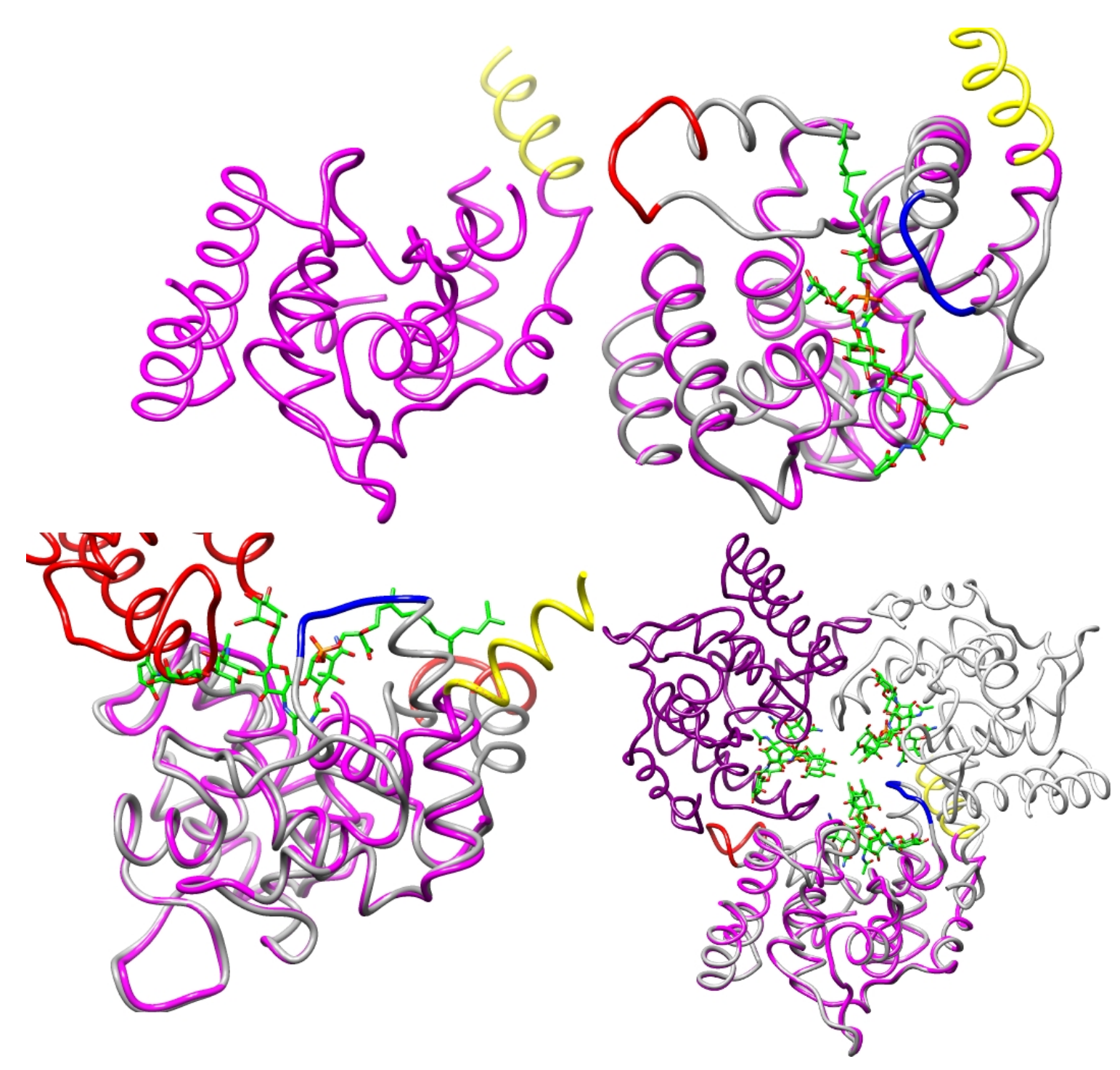

Fig. 2: $3 \mathrm{D}$ structures of $2 \mathrm{MGT}$ and $68 \mathrm{MGT}$. A) Top-left. The 3D structure of $2 \mathrm{MGT}$. Residues belonging to the TM-domain (I53-L64) are colored yellow. B) Top-right. The 3D structure of 2MGT superposed onto the 3D structure of 68MGT with bound moeA (green, colored by heteroatom). Element A: apex colored red. Element B: apex colored blue. C) Bottom-left. As B, but also showing a symmetry related 2MGT molecule (red partial chain) that overlaps with the A, B and D-ring (Fig. 1) of the 68MGT bound moeA molecule. This illustrates that the crystallization of 2MGT precludes the binding of moeA. D) Bottom-right. As B, but shown as part of the 68MGT quarternary structure (a trimer with a diameter of $\sim 80 \AA$ ). The 2MGT TM-domain (yellow) occupies the same coordinates as structural elements of chain $\mathrm{C}$ of the $68 \mathrm{MGT}$ trimer. Chain A-C are colored dark grey, dark magenta, and light grey, respectively. Figures made with Chimera [44] and GIMP. 


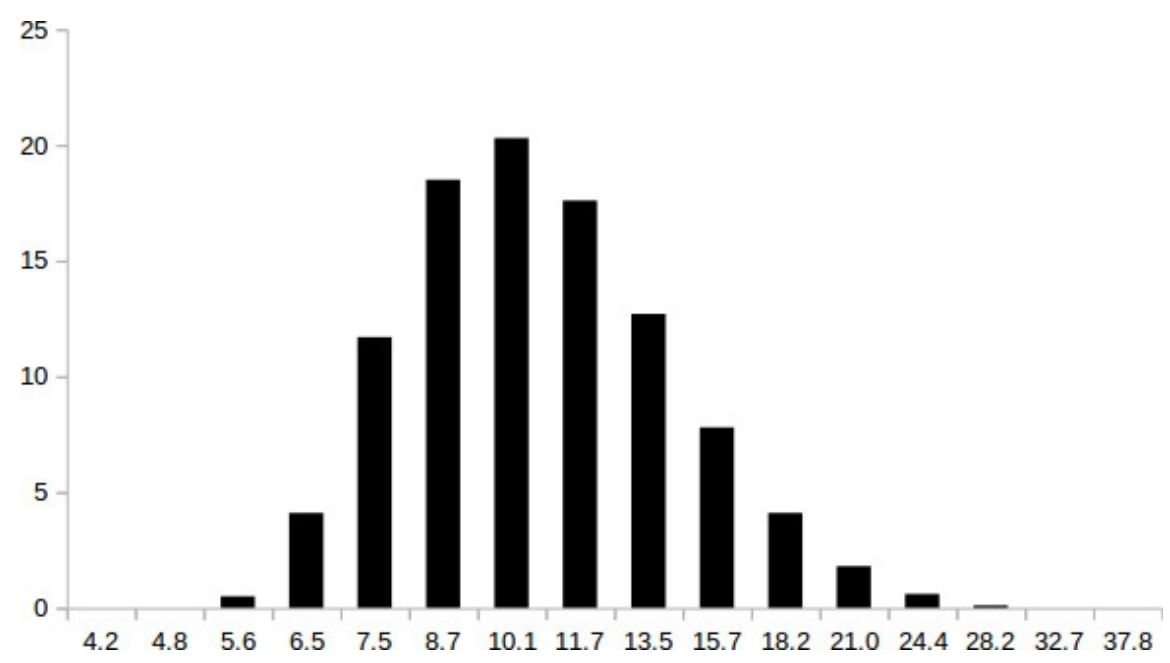

Fig. 3: Polydispersity of 6MGT in assay buffer as measured (in duplo) by dynamic light scattering. X-axes: diameter (nm). Y-axis: volume (\%). A maximum occurs at 10.1 (11.7) nm at $20.3(20.3)$ volume (\%) with a Z-average of $17.7(18.5) \mathrm{nm}$. 

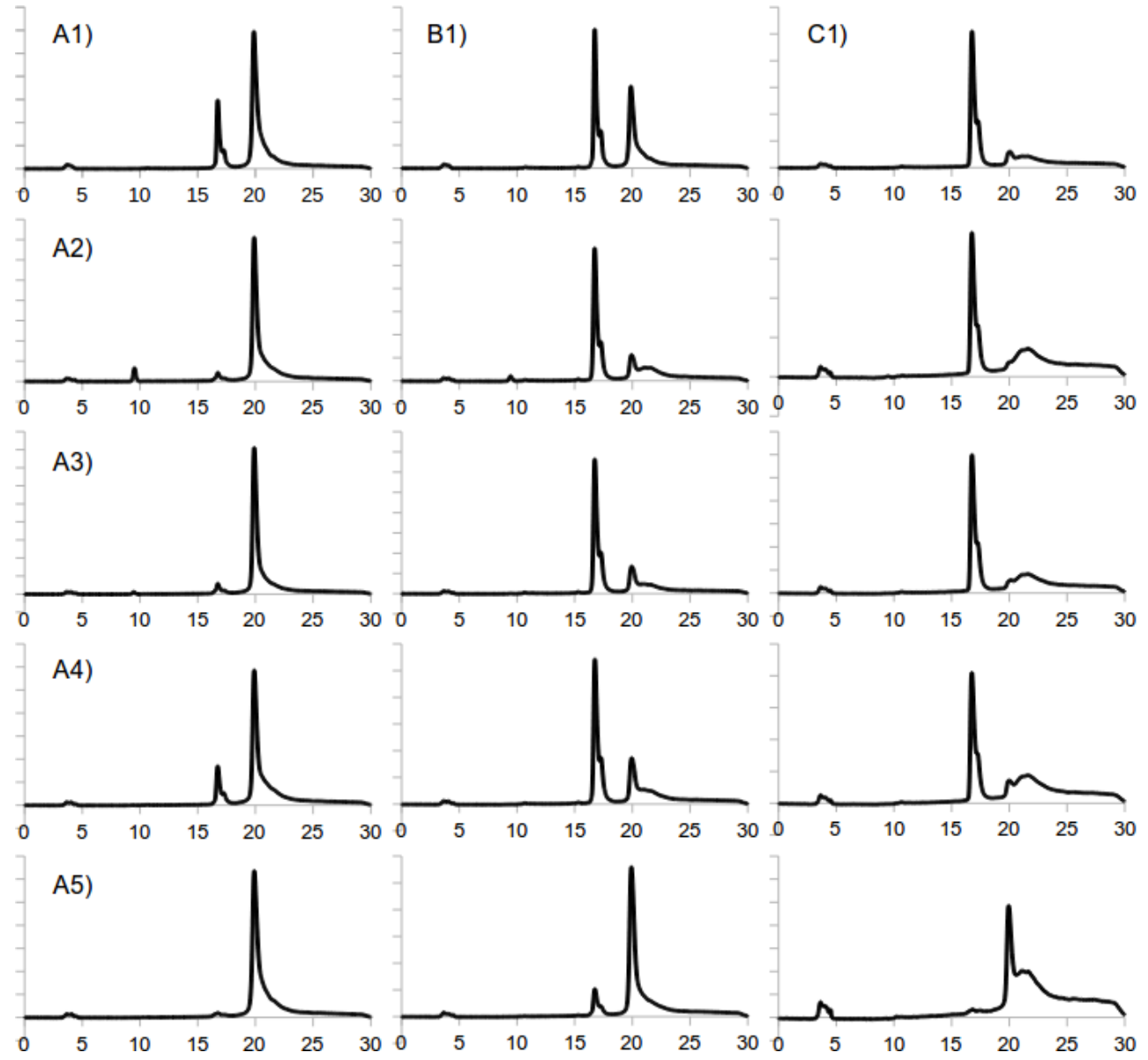

Fig. 4: Ion exchange chromatograms showing the conversion of NBD-lipid II (20.1 ml) into NBDGlcNAc-MurNAc $(16.8 \mathrm{ml})$ by a batch of purified 2MGT and lysozyme under a variety of enzyme assay conditions. A1) $20 \mathrm{mM} \mathrm{Na}$ HEPES pH 7.5, $1 \mathrm{mM} \mathrm{MnCl}_{2}$ and $1.6 \mathrm{mM} \mathrm{C}_{10} \mathrm{E}_{8}$. A2-4) equals A1, plus either 500, 50, or $5 \mu \mathrm{M}$ ppb, respectively. A5) equals A1, plus $1 \mu \mathrm{M}$ moeA. B1-B5) equals A1A5, but with $\mathrm{C}_{10} \mathrm{E}_{8}$ substituted for $2 \mathrm{mM}$ DM. C1-C5) equals B1-B5, but with DM substituted for $0.01 \% \mathrm{v} / \mathrm{v}$ S. aureus lipids. Assay time: $2 \mathrm{hr}$ (A and B), $10 \mathrm{~min}(\mathrm{C}) . \mathrm{X}$-axis: time (min) with a sampling frequency of $5 \mathrm{~Hz}$. Y-axis: fluorescence units (FLU), with an interval of 100, 50 (C2-C4), or 20 (C5) FLU. Figure made with LibreOffice Calc/Draw and GIMP (as well as figs. 5\&6) 


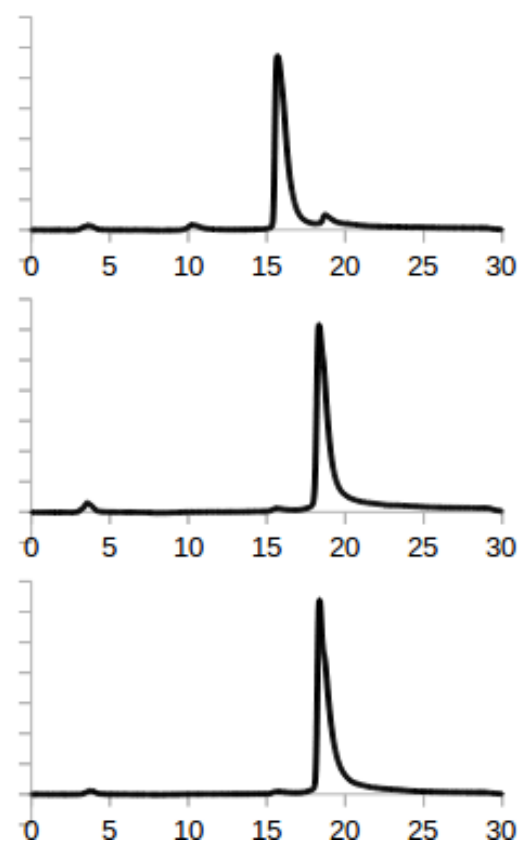

Fig. 5: Ion exchange chromatograms showing the conversion of NBD-lipid II (20.1 ml) into NBDGlcNAc-MurNAc $(16.8 \mathrm{ml})$ by $2 \mathrm{MGT}$ and lysozyme in an assay condition containing A) $20 \mathrm{mM}$ Na HEPES pH 7.5, 1 mM MnCl $2,0.1 \%$ v/v S. aureus lipids (top). B) As A, plus $16 \mu$ M TAN1532B (middle). C) As A, plus $1 \mu \mathrm{M}$ moeA (bottom). Assay time: 10 min. X-axis: time (min). Y-axis: fluorescence units (FLU). Interval: 100 FLU. 


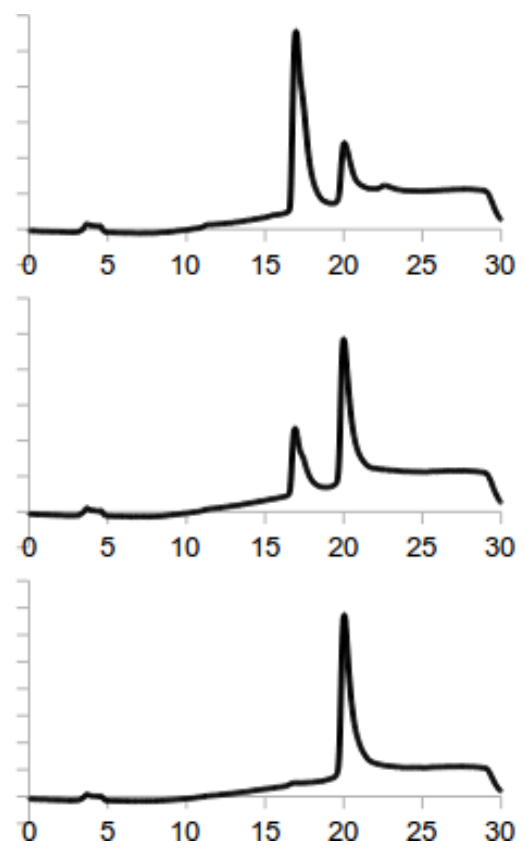

Fig. 6: Ion exchange chromatograms showing the conversion of NBD-lipid II (20.1 ml) into NBDGlcNAc-MurNAc $(16.8 \mathrm{ml})$ by 6MGT and lysozyme in an assay condition containing A) $20 \mathrm{mM}$ $\mathrm{Na}$ HEPES pH 7.5, $200 \mathrm{mM} \mathrm{NaCl}$ and $1 \mathrm{mM} \mathrm{MnCl}_{2}$ (top). B) As A, plus $5 \mu \mathrm{M}$ ppb (middle). C) As A, plus $1 \mu \mathrm{M}$ moeA (bottom). Assay time: $2 \mathrm{hr}$. X-axis: time (min). Y-axis: fluorescence units (FLU). Interval: 50 FLU. 


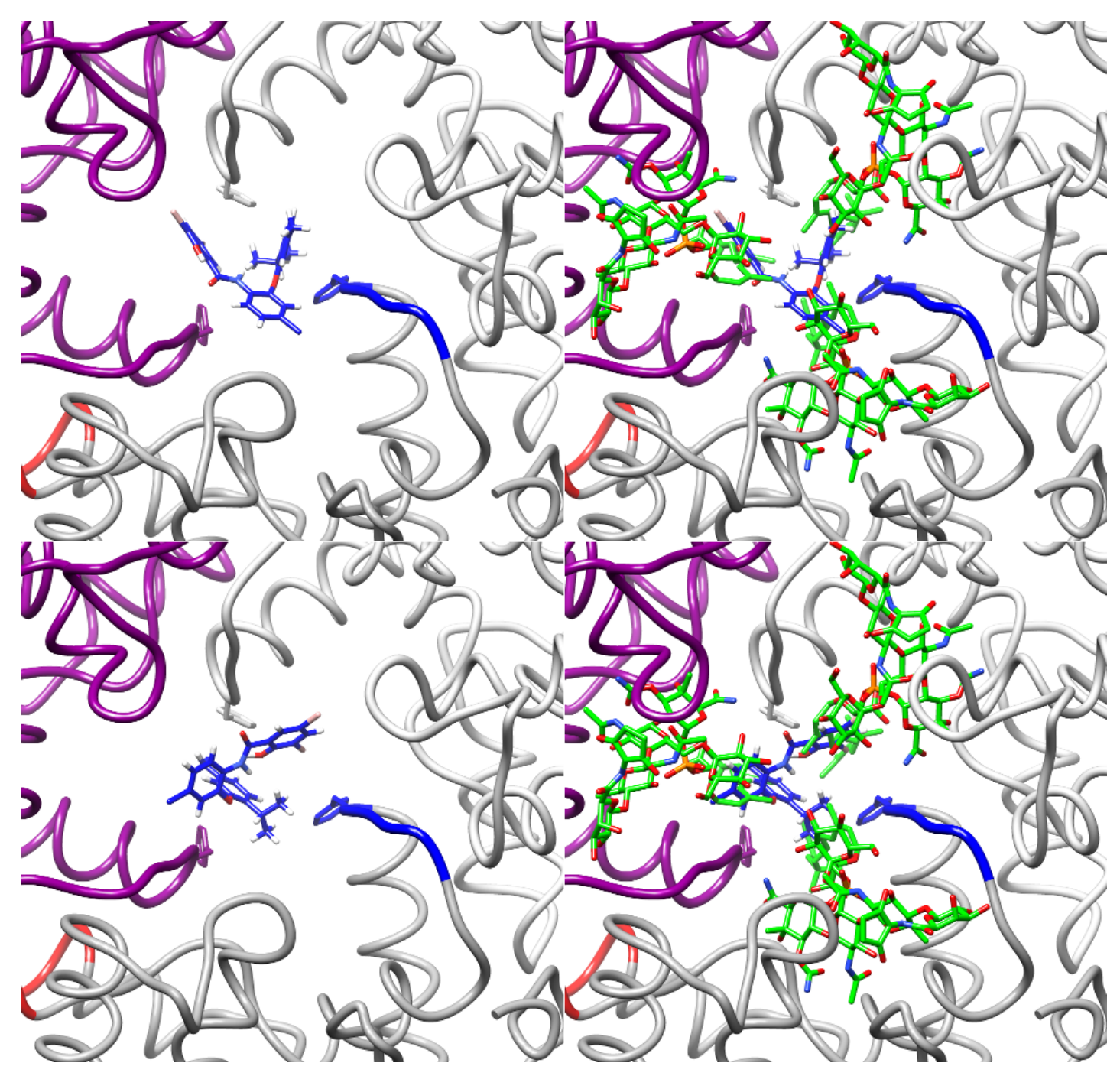

Fig. 7: Modelling of the 68MGT (trimer) ppb interaction. A) Top-left. Ppb (blue, colored by heteroatom, $\Delta \mathrm{G}=-7.91$ ) shown bound (via hydrophobic interactions) in an aromatic pocket lined by three F150's (stick representation) from chains A, B and C (color scheme as in fig. 2D). B) Topright. As A, but also showing bound moeA. C) Bottom-left. As A, but showing a different model $(\Delta \mathrm{G}=-7.88)$. D) Bottom-right. As B. 
bioRxiv preprint doi: https://doi.org/10.1101/292912; this version posted April 11, 2018. The copyright holder for this preprint (which was not certified by peer review) is the author/funder. All rights reserved. No reuse allowed without permission.

\section{Acknowledgements}

We thank the technical services provided by the "Synchrotron Radiation Protein Crystallography Facility of the National Core Facility Program for Biotechnology, Ministry of Science and Technology" and the "National Synchrotron Radiation Research Center", a national user facility supported by the Ministry of Science and Technology of Taiwan, ROC. In addition, GGW would like to thank Guo, ChihWei for help with analyzing Fig. S3. 


\section{References}

1: Taubes G. - The bacteria fight back - Science, 2008, 321(5887), 356-361

2: Perkins H.R. - Chemical structure and biosynthesis of bacterial cell walls - Bacteriol. Rev., $1963,27(1), 18-55$

3: Anderson J.S., Matsuhashi M., Haskin M.A., Strominger J.L. - Lipid-phosphoacetylmuramylpentapeptide and lipid-phosphodisaccharide-pentapeptide: presumed membrane transport intermediates in cell wall synthesis - Proc. Natl. Acad. Sci. U.S.A., 1965, 53(4), 881-889

4: Higashi Y., Strominger J.L., Sweeley C.C. - Biosynthesis of the peptidoglycan of bacterial cell walls. XXI. Isolation of free $\mathrm{C}_{55}$-isoprenoid alcohol and of lipid intermediates in peptidoglycan synthesis from Staphylococcus aureus - J. Biol. Chem., 1970, 245(14), 3697-3702

5: Sauvage S., Kerff F., Terrak M., Ayala J.A., Charlier P. - The penicillin-binding proteins: structure and role in peptidoglycan synthesis - FEMS Microbiol. Rev., 2008, 32(2), 234-258

6: Perlstein D.L., Zhang Y., Wang T.S., Kahne D.E., Walker S. - The direction of glycan chain elongation by peptidoglycan glycosyltransferases - J. Am. Chem. Soc., 2007, 129(42), 1267412675

7: Lovering A.L., de Castro L.H., Lim D., Strynadka N.C.J. - Structural insight into the transglycosylation step of bacterial cell-wall synthesis - Science, 2007, 315(5817), 1402-1405

8: Scheurwater E., Reid C.W., Clarke A.J. - Lytic transglycosylases: bacterial space-making autolysins - Int. J. Biochem. Cell Biol., 2008, 40(4), 586-591

9: King D.T., Strynadka N.C.J. - The mechanism of resistance to $\beta$-lactam antibiotics. In: Gotte M., Sheppard D. (eds) Handbook of antimicrobial resistance, 2017, 177-201, Springer, New York, NY

10: Kong K-F., Schneper, L., Mathee K. - Beta-lactam antibiotics: from antibiosis to resistance and bacteriology - APMIS, 2010, 118(1), 1-36

11: Ostash B., Walker S. - Moenomycin family antibiotics: chemical synthesis, biosynthesis, biological activity - Nat. Prod. Rep., 2010, 27(11), 1594-1617

12: Zuegg J., Muldoon C., Adamson G., McKeveney D., Le Thanh G., Premraj R., Becker B., Cheng M., Elliot A.G., Huang J.X., Butler M.S., Bajaj M., Seifert J., Singh L., Galley N.F., Roper D.I., Lloyd A.J., Downson C.G., Cheng T.J., Cheng W.C., Demon D., Meyer E., Meutermans W., Cooper, M.A. - Carbohydrate scaffolds as glycosyltransferase inhibitors with in vivo antibacterial activity - Nat. Commun., 2015, doi: 10.1038/ncomms8719

13: Dumbre S., Derouaux A., Lescrinier E., Piette A., Joris B., Terrak M., Herdewijn, P. - Synthesis of modified peptidoglycan precursor analogues for the inhibition of glycosyltransferases - J. Am. Chem. Soc., 2012, 134(22), 9343-9351 
14: Derouaux A., Sauvage E., Terrak M. - Peptidoglycan glycosyltransferase substrate mimics as templates for the design of new antibacterial drugs - Front. Immunol., 2013, doi: 10.3389/fimmu.2013.00078

15: Cheng T-J., Wu Y-T, Yang S-T, Lo K-H, Chen S-K, Chen Y-H, Huang W-I, Yuan C-H, Guo, CW, Huang L-Y, Chen K-T, Shih H-W, Cheng Y-S, Cheng W-C, Wong C-H. - High-throughput identification of antibacterials against methicillin-resistant Staphylococcus areus (MRSA) and the transglycosylase - Bioorg. Med. Chem., 2010, 18(24), 8512-8529

16: Wu W-S., Cheng W-C, Cheng T-R, Wong C-H. - Affinity-based screen for inhibitors of bacterial transglycosylase - J. Am. Chem. Soc., 2018, 140(8), 2752-2755

17: Bradford M.M. - A rapid and sensitive method for the quantitation of microgram quantities of protein utilizing the principle of protein-dye binding - Anal. Biochem., 1976, 72(1-2), 248-254

18: Ujwal R., Bowie J.U. - Crystallizing membrane proteins using lipidic bicelles - Methods, 2011, 55(4), 337-341

19: Battye T.G.G., Kontogiannis L., Johnson O., Powel H.R., Leslie, A.G.W. - iMOSFLM: a new graphical interface for diffraction-image processing with MOSFLM - Acta Crystallogr. D Biol. Crystallogr., 2011, 67(4), 271-281

20: Strong M., Sawaya M.R., Wang S., Phillips M., Cascio D., Eisenberg D. - Toward the structural genomics of complexes: Crystal structure of PE/PPE protein complex from Mycobacterium tuberculosis - Proc. Natl. Acad. Sci. U.S.A., 2006, 103(21), 8060-8065

21: Matthews B.W. - Solvent content of protein crystals - J. Mol. Biol., 1968, 33(2), 491-497

22: McCoy A.J., Grosse-Kunstleve R.W., Adams P.D., Winn M.D., Storoni L.C., Read R.J. - Phaser crystallographic software - J. Appl. Cryst., 2007, doi: 10.1107/S0021889807021206

23: Huang C-Y., Shih H.W., Lin L-Y, Tien Y-W, Cheng T-J, Cheng W-C, Wong C-H, Ma C. Crystal structure of Staphylococcus areus transglycosylase in complex with a lipid II analog and elucidation of peptidoglycan synthesis mechanism - Proc. Natl. Acad. Sci. U.S.A., 2012, 109(17), 6496-6501

24: Murshudov G.N., Vagin A.A., Dodson E.J. - Refinement of macromolecular structures by maximum-likelihood method - Acta Crystallogr. D Biol. Crystallogr., 1997, doi: $10.1107 / \mathrm{S} 0907444996012255$

25: Emsley P., Lohkamp B., Scott W.G., Cowtan K., - Features and development of Coot - Acta Crystallogr. D Biol. Crystallogr., 2010, doi: 10.1107/S0907444910007493

26: Winn M.D., Ballard C.C., Cowtan K.D., Dodson E.J., Emsley P., Evans P.R., Keegan R.M., Krissinel E.B., Leslie A.G., McCoy A., McNicholas S.J., Murshudov G.N., Pannu N.S., Potterton 
E.A., Powell H.R., Read R.J., Vagin A., Wilson K.S. - Overview of the CCP4 suite and current developments - Acta Crystallogr. D Biol. Crystallogr., 2011, doi: 10.1107/S0907444910045749

27: Kall L., Krogh A., Sonnhammer E.L. - A combined transmembrane topology and signal peptide prediction method - J. Mol. Biol., 2004, 338(5), 1027-1036

28: Kurz M., Guba W., Vertesy L. - The three-dimensional structure of moenomycin A, a potent inhibitor of penicillin-binding protein 1b - Eur. J. Biochem., 1998, 252(3), 500-507

29: Hara A., Radin N.S. - Lipid extraction of tissues with a low-toxicity solvent - Anal. Biochem., 1978, 90(1), 420-426

30: Tsai M., Ohniwa R.L., Kato Y., Takeshita S.L., Ohta T., Saito S., Hayashi H., Morikawa K. Staphylococcus aureus requires cardiolipin for survival under conditions of high salinity - BMC Microbiol., 2011, doi: 10.1186/1471-2180-11-13

31: Schuttelkopf A.W., van Aalten D.M. - PRODRG: a tool for high-throughput crystallography of protein-ligand complexes - Acta Crystallogr. D Biol. Crystallogr., 2004, doi: $10.1107 / \mathrm{S} 0907444904011679$

32: Grosdidie, A., Zoete V., Michielin O. - SwissDock, a protein-small molecule docking web service based on EADock DSS - Nucleic Acids Res., 2011, doi: 10.1093/nar/gkr366

33: Heaslet H., Shaw B., Mistry A., Miller A.A. - Characterization of the active site of S. aureus monofunctional glycosyltransferase (Mtg) by site-directed mutation and structural analysis of the protein complexed with moenomycin - J. Struct. Biol., 2009 167(2), 129-135

34: Krissinel E., Henrick K. - Inference of macromolecular assemblies from crystalline state - J. Mol. Biol., 2007, 372(3), 774-797

35: Wang Q.M., Peery R.B., Johnson R.B., Alborn W.E., Yeh W.K., Skatrud P.L. - Identification and characterization of a monofunctional glycosyltransferase from Staphylococcus aureus - J. Bacteriol., 2001, 183(16), 4779-4785

36: Terrak M., Nguyen-Disteche M. - Kinetic characterization of the monofunctional glycosyltransferase from Staphylococcus aureus - J. Bacteriol., 2006, 188(7), 2528-2532

37: Yuan Y., Barrett D., Zhang Y., Kahne D. Sliz P., Walker S. - Crystal structure of a peptidoglycan glycosyltransferase suggests a model for processive glycan chain synthesis - Proc. Natl. Acad. Sci. U.S.A., 2007, 104(13), 5348-5353

38: Luo J., Liu Z., Guo Y., Li M. - A structural dissection of large protein-protein crystal packing contacts - Sci. Rep., 2015, doi: 10.1038/srep14214

39: Bisswanger H. - Enzyme assays - Pers. in Sci., 2014, doi: 10.1016/j.pisc.2014.02.005

40: Feng B.Y., Shoichet, B.K. - A detergent-based assay for the detection of promiscuous inhibitors - Nat. Protoc., 2006, 1(2), 550-553 
41:Kolarovic L., Fournier N.C. - A comparison of extraction methods for the isolation of phospholipids from biological sources - Anal. Biochem., 1986, 156(1), 244-250

42: Newman M.J., Wilson T.H. - Solubilization and reconstitution of the lactose transport system from Escherichia coli - J. Biol. Chem., 1980, 255(22), 10583-10586

43: Baell J., Walters M.A. - Chemical con artists foil drug discovery - Nature, 2014, 513(7519), $481-483$

44: Pettersen E.F., Goddard T.D., Huang C.C., Couch G.S., Greenblatt D.M., Meng E.C., Ferrin T.E. - UCSF Chimera-A visualization system for exploratory research and analysis - J. Comput. Chem., 2004, 25(13), 2004, 1605-1612 